\title{
Nocturnal hypoxemia in children and adolescents with cystic fibrosis*
}

\author{
Hipoxemia noturna em crianças e adolescentes com fibrose cística
}

\author{
Regina Terse Trindade Ramos, Maria Angélica Pinheiro Santana, \\ Priscila de Carvalho Almeida, Almério de Souza Machado Júnior, \\ José Bouzas Araújo-Filho, Cristina Salles
}

\begin{abstract}
Objective: To determine the prevalence of nocturnal hypoxemia and its association with pulmonary function, nutritional status, sleep macrostructure, and obstructive respiratory events during sleep in a population of clinically stable children and adolescents with cystic fibrosis (CF). Methods: This was a cross-sectional study involving 67 children and adolescents with CF between 2 and 14 years of age. All of the participants underwent polysomnography, and $\mathrm{SpO}_{2}$ was measured by pulse oximetry. We also evaluated the Shwachman-Kulczycki (S-K) scores, spirometry findings, and nutritional status of the patients. Results: The study involved 67 patients. The mean age of the patients was 8 years. The S-K scores differed significantly between the patients with and without nocturnal hypoxemia, which was defined as an $\mathrm{SpO}_{2}<90 \%$ for more than 5\% of the total sleep time $(73.75 \pm 6.29$ vs. $86.38 \pm 8.70 ; p<0.01)$. Nocturnal hypoxemia correlated with the severity of lung disease, FEV $_{1}\left(r_{s}=-0.42 ; p=0.01\right)$, FVC $\left(r_{s}=-0.46 ; p=0.01\right)$, microarousal index $\left(r_{s}=0.32 ; p=0.01\right)$, and apneahypopnea index $\left(r_{s}=0.56 ; p=0.01\right)$. Conclusions: In this sample of patients with $C F$ and mild-to-moderate lung disease, nocturnal oxygenation correlated with the S-K score, spirometry variables, sleep macrostructure variables, and the apnea-hypopnea index.
\end{abstract}

Keywords: Cystic fibrosis; Sleep; Oximetry.

\section{Resumo}

Objetivo: Determinar a prevalência de hipoxemia noturna e sua associação com função pulmonar, estado nutricional, macroestrutura do sono e eventos respiratórios obstrutivos durante o sono em uma população de crianças e adolescentes com fibrose cística (FC) clinicamente estáveis. Métodos: Estudo de corte transversal envolvendo 67 crianças e adolescentes com FC e idade entre 2 e 14 anos. Todos os participantes foram submetidos a polissonografia com medição da $\mathrm{SpO}_{2}$ por oximetria de pulso. $\mathrm{O}$ escore de Shwachman-Kulczycki (S-K), a espirometria e o estado nutricional dos pacientes também foram avaliados. Resultados: Foram incluídos 67 pacientes. A média de idade foi de 8 anos. Os resultados do escore de S-K diferiram significativamente entre os pacientes com e sem hipoxemia noturna, definida como $\mathrm{SpO}_{2}<90 \%$ por mais que 5\% do tempo total de sono $(73,75 \pm 6,29$ vs. $86,38 \pm 8,70 ; p<0,01)$. A presença de hipoxemia noturna correlacionou-se com a gravidade da doença pulmonar, $\operatorname{VEF}_{1}\left(r_{s}=-0,42 ; p=0,01\right)$, CVF $\left(r_{s}=-0,46 ; p=0,01\right)$, índice de microdespertares do sono $\left(r_{s}=0,32 ; p=0,01\right)$ e índice de apneia e hipopneia $\left(r_{s}=0,56 ; p=0,01\right)$. Conclusões: Nesta amostra de pacientes com FC e doença pulmonar leve a moderada, o nível de oxigenação noturna correlacionou-se com escore de S-K, variáveis espirométricas e da macroestrutura do sono, assim como o índice de apneia e hipopneia. Descritores: Fibrose cística; Sono; Oximetria.

*Study carried out in the Department of Pediatrics, Federal University of Bahia School of Medicine, Salvador, Brazil. Correspondence to: Regina Terse Trindade Ramos. Faculdade de Medicina - Sede Mater, Departamento de Pediatria, Largo do Terreiro de Jesus, s/n, Pelourinho, CEP 40026-010, Salvador, BA, Brasil.

Tel. 5571 3332-6182. E-mail: reginaterse@yahoo.com

Financial support: None.

Submitted: 4 June 2013. Accepted, after review: 10 October 2013. 


\section{Introduction}

Cystic fibrosis (CF) is a multisystem autosomal recessive genetic disease that primarily affects the epithelia of various organs, leading to significant morbidity and mortality. It results from a mutation in the gene encoding the cystic fibrosis transmembrane conductance regulator protein, with approximately $250 \mathrm{~kb}$, and located on the long arm of chromosome 7. Abnormal ion transport causes dehydration of luminal secretions, with formation of viscous mucus and subsequent stasis. This defect impairs mucociliary clearance, leading to chronic infection, airway remodeling, and, consequently, to air trapping, an imbalance in the ventilation/perfusion ratio, and increased work of breathing. ${ }^{(1)}$ There is progressive airflow obstruction due to mucus plugging and inflammation within the bronchial walls, with bronchiectasis and destruction of lung parenchyma. Despite continuous improvement in the care of patients with CF, much of the morbidity and mortality result from lung disease, the end stage of which is characterized by hypercapnic respiratory failure. ${ }^{(2)}$

During sleep, there are drops in oxyhemoglobin saturation, and these occur primarily during rapid eye movement sleep; in patients with $\mathrm{CF}$, these drops are associated with a decrease in intercostal muscle activity, with breathing pattern irregularity, and with hypoventilation caused by a reduction in tidal volume and minute ventilation. ${ }^{(3)}$ Episodic hypoxemia can occur during sleep, as well as during exercise and during CF infectious exacerbations. There are reports of its occurrence during sleep and during exercise in clinically stable adult patients with $\mathrm{CF}$, who do not exhibit daytime hypoxemia. ${ }^{(4)}$ However, there has been reference to severe episodes of oxyhemoglobin desaturation during sleep in adolescents and adults with CF, and hypoxemia can be a stimulus for disruption of normal sleep patterns and quality of life in these patients. ${ }^{(3)}$ Evidence in the literature suggests that hypoxemia plays a role in the pathogenesis of lung injury and in cor pulmonale in these patients, as do brief episodes of desaturation, which can increase pulmonary artery pressure. ${ }^{(5)}$ Hypoxemia in these patients is potentially important because it leads to clinical complications, such as pulmonary hypertension and right heart failure; evidence suggests that hypoxemia can exacerbate lung inflammation and affect the bacterial profile of the lung in these patients. ${ }^{(6,7)}$

The definitions of hypoxemia during sleep vary among different countries and among published studies in the medical literature; some authors define it as a pulse oximetry-measured arterial oxyhemoglobin saturation $\left(\mathrm{SpO}_{2}\right)<90 \%$ for more than $5 \%$ of the total sleep time (TST), whereas others define it as an $\mathrm{SpO}_{2}<90 \%$ for more than $30 \%$ of TST. ${ }^{(8)}$ The lack of a clear definition of "significant hypoxemia" during sleep makes it difficult to determine its prevalence and severity. In adults, $\mathrm{PaO}_{2}$ measurement is considered crucial; however, this measurement is not always considered to be practical or possible in children. In pediatric practice, arterial oxyhemoglobin saturation measured by pulse oximetry remains the main tool. ${ }^{(1)}$

Considering the few existing reports in the literature that address abnormalities resulting from nocturnal hypoxemia in pediatric patients with $\mathrm{CF}$, our objective was to estimate the prevalence of nocturnal hypoxemia and correlate it with abnormalities in sleep macrostructure, pulmonary function data, nutritional status, and obstructive respiratory events during sleep in a sample of children with CF.

\section{Methods}

This was a prospective, cross-sectional and descriptive-analytical study. We evaluated 67 children and adolescents with CF, who were under follow-up and were consecutively recruited at a referral center for the treatment of CF, between November of 2006 and April of 2008. Patients self-reported their skin color as being white, black, light brown, medium brown, or dark brown. ${ }^{(9)}$ A diagnosis of CF was confirmed by at least two abnormal sweat chloride results.

The study involved male and female patients aged 2 to 14 years who agreed to participate and whose parents or legal guardians gave written informed consent. The exclusion criteria were as follows: having undergone oral or intravenous antibiotic therapy in the month prior to the study's outset and having experienced pulmonary exacerbation in that period; having comorbidities, such as diabetes mellitus, gastroesophageal reflux disease, sleep-disordered breathing, genetic disease, primary cardiac disease, neuromuscular disease, craniofacial anomalies, psychiatric disease, and Down syndrome; being on enteral or parenteral 
feeding, antidepressants, hypnotics, and home oxygen therapy; and having undergone lung transplantation.

The following instruments were used for clinical and functional assessment of the patients.

Disease severity was assessed by the Shwachman-Kulczycki (S-K) score, which is based on four major criteria-general activity, nutrition, radiological findings, and physical examination. The overall score ranges from 20 to 100 , with patient's status being classified as excellent (score, 86-100), good (score, 71-85), average (56-70), poor (score, 41-55), or severe (score, $\leq 40) .{ }^{(10)}$

For assessment of nutritional status, height and weight were measured, and the values obtained were compared with data from the United States National Center for Health Statistics and converted to $\mathrm{z}$ scores for weight/age, height/ age, and weight/height, on the basis of age and gender, by using Epi Info software program, version 3.4.1; malnutrition was defined as weight $\mathrm{z}$ scores below two standard deviations. In addition, we evaluated body mass index, calculated as weight in kilograms divided by height in meters squared $\left(\mathrm{kg} / \mathrm{m}^{2}\right) .{ }^{(11)}$

Overnight polysomnography was performed in a standardized fashion with the use of a computerized system (BrainNet BNTÒ; LYNX Tecnologia Eletrônica, Rio de Janeiro, Brazil), which included electroencephalography, electrooculography, leg and mentalis electromyography, measurement of airflow with an oronasal thermistor and a nasal cannula, and pulse oximetry (Onyx ${ }^{\circledR} 11$ 9650 Bluetooth; Nonim Medical Inc., Plymouth, MN, USA). We estimated $\mathrm{SpO}_{2}$ as the mean of at-rest values obtained over a five-minute period, with the patient being in a sitting position and awake, at initiation of the sleep study. A desaturation event was defined as a decrease of $4 \%$ or more in $\mathrm{SpO}_{2}$. Mean and minimum $\mathrm{SpO}_{2}$ were determined. Analysis of sleep stages, analysis of microarousals, and scoring of respiratory events during sleep were performed in accordance with the recommendations of the American Academy of Sleep Medicine. ${ }^{(12)}$ Although controversy surrounds the definition of nocturnal hypoxemia, we chose to define it as an $\mathrm{SpO}_{2}<90 \%$ for more than $5 \%$ of TST, with a nadir of at least $85 \%$; these values were based on previous investigations in patients with $\mathrm{CF} .{ }^{(8)}$
Spirometry was performed with a Microlab Spirometer 3500K, version 5.X.X Carefusion (Micro Medical Ltd., Rochester, United Kingdom), in accordance with the criteria established by the American Thoracic Society ${ }^{(13)}$ and the Brazilian Thoracic Association, ${ }^{(14)}$ in patients $\geq 6$ years of age. The parameters studied were FVC, FEV , and $\mathrm{FEF}_{25-75 \%}$, expressed as a percentage of predicted for gender, age, and height, in accordance with the Knudson et al. equation for children and adolescents. ${ }^{(15)}$

To build the database and perform the statistical calculations, we used the Statistical Package for the Social Sciences, version 13.0 (SPSS Inc., Chicago, IL, USA). ${ }^{(16)}$ Continuous variables are expressed as median (interquartile range) or mean (standard deviation), whereas categorical variables are expressed as frequency and proportion. The chi-square test and Fisher's exact test were used for the comparison of proportions. Means were compared by the Student's t-test (for variables with normal distribution) or the Mann-Whitney test (for variables without normal distribution). Correlations of TST spent at an $\mathrm{SpO}_{2}<90 \%$ with pulmonary function variables and polysomnography variables were calculated by Spearman's linear correlation coefficient $\left(\mathrm{r}_{\mathrm{s}}\right)$, which measures the degree of association between two numerical variables. This coefficient ranges from -1 to 1 ; values closer to -1 or 1 indicate a stronger association between the two variables, and values closer to zero indicate a weaker relationship. Values of $p<0.05$ were considered statistically significant.

The present study was approved by the Research Ethics Committee of the Oswaldo Cruz Foundation (Ruling no. 119/2007). Polysomnography was performed during spontaneous sleep, and parents remained with their children during the procedure. The present study did not contravene the ethical precepts regarding research. All of the participants received verbal and written information on the nature and purpose of the study and gave written informed consent.

\section{Results}

The Referral Center for Cystic Fibrosis of the Octávio Mangabeira Specialized Hospital follows 200 adult and pediatric patients. We interviewed 85 pediatric patients with CF in order to possibly involve them in the study, and, of the 74 who were considered eligible, only 67 agreed 
to participate in the study. The study sample consisted of clinically stable children, most of whom were male and self-reported their skin color as being black or brown. The demographic data of the study population are shown in Table 1 .

The means of mean $\mathrm{SpO}_{2}$ and of $\mathrm{SpO}_{2}$ nadir, during sleep, were $94.3 \pm 2.1 \%$ and $81.2 \pm 5.9 \%$, respectively. Maximum sleep time spent at an $\mathrm{SpO}_{2}<90 \%$ was 221 minutes (53\% of TST), and only one patient had an $\mathrm{SpO}_{2} \leq 80 \%$ for 11 minutes (4.5\% of TST). We found that 18 patients (26.9\%) had an $\mathrm{SpO}_{2}<85 \%$ during sleep and that only $11(16.4 \%)$ did not have any nocturnal desaturation events.

The patients were divided into two groups on the basis of their having or not having the outcome of interest, i.e., nocturnal hypoxemia, which was defined as an $\mathrm{SpO}_{2}<90 \%$ for more than $5 \%$ of TST, with a nadir of at least $85 \%$. The group with nocturnal hypoxemia consisted of 4 patients ( $6 \%$, Table 2). The two groups were compared regarding clinical characteristics, demographic characteristics, and polysomnography findings. Analysis of the $\mathrm{z}$ scores for weight/ age, height/age, and weight/height revealed no statistically significant differences between the groups. However, FEV , FVC, and S-K score values were significantly lower in the patients with nocturnal hypoxemia than in those without nocturnal hypoxemia (Table 2 ).

A comparison of the two groups regarding polysomnography findings showed that the group with nocturnal hypoxemia spent a greater proportion of time in stage R sleep; however, all other sleep architecture parameters were similar between the groups. Nine patients (13.4\%) had an apnea-hypopnea index $(\mathrm{AHI}) \geq 5$, and mean

Table 1 - Demographic and clinical data of the 67 cystic fibrosis patients studied. ${ }^{\mathrm{a}}$

\begin{tabular}{|c|c|}
\hline Characteristic & Result \\
\hline Male gender & 38 (56.7) \\
\hline Age, years ${ }^{b}$ & $8(5-10)$ \\
\hline Black or brown skin color & $54(80.6)$ \\
\hline z score for weight/age ${ }^{b}$ & $-0.54(-1.3$ to 0.2$)$ \\
\hline z score for height/age ${ }^{b}$ & $-0.50(-1.0$ to 0.5$)$ \\
\hline BMl percentileb & $34(11-64)$ \\
\hline Total S-K score ${ }^{\mathrm{C}}$ & $85.6 \pm 9.1$ \\
\hline $\mathrm{FEV}_{1}, 0$ of predicted ${ }^{\mathrm{b}}$ & $78.5(67.0-92.8)$ \\
\hline
\end{tabular}

BMl: body mass index; and S-K score: Shwachman-Kulczycki

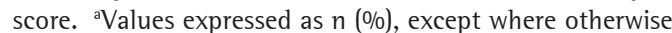
indicated. bValues expressed as median (interquartile range). 'Values expressed as mean \pm SD.
$\mathrm{AHI}$ was found to be higher in the group with nocturnal hypoxemia than in the group without nocturnal hypoxemia ( $12.8 \pm 11.4$ vs. $3.7 \pm 3.1)$, although not statistically significantly so (Table 2 ).

According to Spearman's correlation coefficient, the period of time with $\mathrm{SpO}_{2}<90 \%$ for more than 5\% of TST correlated significantly with FEV $_{1}\left(r_{s}=-0.42 ; p=0.01\right)$, FVC $\left(r_{s}=-0.46 ; p=\right.$ $0.01)$, microarousal index $\left(r_{s}=0.32 ; p=0.01\right)$, and $\mathrm{AHI}\left(r_{s}=0.56 ; p=0.01\right.$; Figure 1$)$.

\section{Discussion}

In the present study, $6 \%$ of the 67 clinically stable children with CF were shown to have hypoxemia during sleep, which was characterized as an $\mathrm{SpO}_{2}<90 \%$ for more than 5\% of TST, whereas $26.9 \%$ of the children studied had significant nocturnal desaturation events $\left(\mathrm{SpO}_{2}<85 \%\right)$. These events were found to be associated with lower S-K scores, lower FVC (\% of predicted), and lower $\mathrm{FEV}_{1}(\%$ of predicted), as well as with a greater proportion of time spent in stage $R$ sleep. There was no association between these events and nutritional status. We found that the period of time with $\mathrm{SpO}_{2}<90 \%$ for more than 5\% of TST correlated negatively with FVC ( $\%$ of predicted) and $\mathrm{FEV}_{1}(\%$ of predicted) and positively with microarousal index and $\mathrm{AHI}$.

Uyan et al. ${ }^{(17)}$ evaluated children aged 8 to 12 years with $\mathrm{CF}$ and mild or moderate lung disease and reported higher mean values for mean and minimum $\mathrm{SpO}_{2}$ than those observed in our study $(96.1 \pm 1.3 \%$ and $88.9 \pm 3.9 \%$ vs. $94.3 \pm 2.1 \%$ and $81.2 \pm 5.9 \%$, respectively). We studied patients aged 2 to 14 years and observed intermittent and frequent drops in $\mathrm{SpO}_{2}$, even in younger individuals with normal or slightly abnormal pulmonary function test results. Of the 67 patients studied, 56 (83.6\%) had desaturation during sleep, most of whom had more than six desaturation events during the monitoring period.

Villa et al., ${ }^{(4)}$ who studied young children with $\mathrm{CF}$, showed that even those with mild lung disease had nocturnal oxyhemoglobin desaturation. Oxyhemoglobin desaturation has been reported to be more prevalent in patients with CF and severe lung disease, but there is limited information on nocturnal $\mathrm{SpO}_{2}$ in patients with $\mathrm{CF}$ and milder lung disease. ${ }^{(8)}$ Castro-Silva et al. ${ }^{(18)}$ studied 30 patients with CF and clinically significant lung disease and compared them 
Table 2 - Comparisons of demographic, clinical, functional, and polysomnography characteristics in relation to total sleep time spent at an $\mathrm{SpO}_{2}<90 \%$ in the patients studied. ${ }^{a}$

\begin{tabular}{|c|c|c|c|}
\hline \multirow[t]{3}{*}{ Characteristic } & \multicolumn{2}{|c|}{ Hypoxemia during sleep ${ }^{b}$} & \multirow[t]{3}{*}{$p^{*}$} \\
\hline & Yes & No & \\
\hline & $(n=4)$ & $(n=63)$ & \\
\hline Age, months & $99.75 \pm 61.52$ & $93.01 \pm 37.14$ & 0.74 \\
\hline Hospitalizations in the last year & $1.25 \pm 1.89$ & $0.63 \pm 1.21$ & 0.34 \\
\hline Episodes of pneumonia in the last year & $1.00 \pm 1.89$ & $0.75 \pm 1.16$ & 0.67 \\
\hline S-K score & $73.75 \pm 6.29$ & $86.38 \pm 8.70$ & $<0.01$ \\
\hline Z score for height/age & $-0.19 \pm 2.16$ & $-0.28 \pm 1.27$ & 0.89 \\
\hline Z score for weight/age & $-1.19 \pm 2.41$ & $-0.48 \pm 1.12$ & 0.60 \\
\hline Z score for weight/height & $-0.91 \pm 1.56$ & $-0.24 \pm 0.92$ & 0.19 \\
\hline Z score for BMl & $-0.78 \pm 1.83$ & $-0.45 \pm 1.35$ & 0.64 \\
\hline FVC, $\%$ of predicted & $43.00 \pm 21.21$ & $81.14 \pm 17.31$ & $<0.01$ \\
\hline $\mathrm{FEV}_{1}, \%$ of predicted & $49.00 \pm 26.87$ & $79.59 \pm 17.37$ & 0.02 \\
\hline $\mathrm{FEF}_{25-75 \%}, \%$ of predicted & $44.00 \pm 18.38$ & $72.19 \pm 25.81$ & 0.14 \\
\hline Sleep efficiency, \% & $84.00 \pm 6.22$ & $80.75 \pm 11.48$ & 0.58 \\
\hline Latency to sleep onset, min & $16.75 \pm 11.70$ & $25.98 \pm 34.55$ & 0.60 \\
\hline Latency to REM sleep, min & $100.50 \pm 51.86$ & $171.07 \pm 111.78$ & 0.22 \\
\hline Microarousal index, per hour of sleep & $9.25 \pm 6.40$ & $6.71 \pm 2.99$ & 0.49 \\
\hline TST spent in stage N1, \% & $6.00 \pm 3.27$ & $7.56 \pm 4.00$ & 0.45 \\
\hline TST spent in stage $\mathrm{N} 2, \%$ & $40.75 \pm 7.41$ & $39.63 \pm 11.47$ & 0.42 \\
\hline TST spent in stage N3, \% & $20.50 \pm 13.63$ & $21.63 \pm 6.53$ & 0.88 \\
\hline TST spent in REM sleep, \% & $21.75 \pm 1.71$ & $14.68 \pm 7.70$ & $<0.0001$ \\
\hline $\mathrm{AHI}$ & $12.75 \pm 11.35$ & $3.73 \pm 3.09$ & 0.21 \\
\hline
\end{tabular}

S-K score: Shwachman-Kulczycki score; BMI: body mass index; REM: rapid eye movement; TST: total sleep time; N: non-REM sleep; and AHI: apnea-hypopnea index. ${ }^{a}$ Values expressed as mean \pm SD. ${ }^{b}$ Hypoxemia during sleep was defined as an $\mathrm{SpO}_{2}<90 \%$ for more than 5\% of TST. *Student.'s t-test

with 10 patients with $\mathrm{CF}$ and less severe lung disease and with 20 controls. The mean ages in the three groups were 12.8 years, 13.3 years, and 15.5 years, respectively. In the group with clinically significant lung disease, 5 patients $(15 \%)$ had an $\mathrm{SaO}_{2}<90 \%$ for more than $30 \%$ of TST, and $11(36.6 \%)$ had an $\mathrm{SaO}_{2}$ nadir < $85 \%$. That study found no differences in sleep macrostructure between the group with clinically significant lung disease and the group with mild lung disease. Unlike our study, which evaluated a younger population, that study observed greater nocturnal desaturation, and it is possible that these findings indicate a population with longer disease duration and greater involvement of the respiratory tract.

One group of authors ${ }^{(5)}$ compared young adult CF patients with and without nocturnal desaturation and observed that those with desaturation experienced a decrease in $\mathrm{SaO}_{2}$ and an increase in $\mathrm{PaCO}_{2}$ during sleep, as well as decrease in $\mathrm{FEV}_{1}$, relative to those without desaturation. Perin et al. ${ }^{(19)}$ showed similar findings, because, in the comparison of patients with and without nocturnal desaturation, there were significantly lower values for FEV 1 (46.4 $\pm 13.6 \%$ vs. $66.9 \pm 23.0 \%)$, FVC ( $35.8 \pm 11.4 \%$ vs. 79.6 $\pm 19.1 \%)$, the S-K score $(62.7 \pm 9.0$ vs. $73.9 \pm$ 11.8), and daytime $\mathrm{SpO}_{2}(92.2 \pm 1.3 \%$ vs. $96.4 \pm$ $1.2 \%$ ), these data being similar to our findings. Those authors also observed that, among the patients with desaturation, there was a greater proportion of pulmonary hypertension. There have been reports of significant repercussions of nocturnal hypoxemia on the pulmonary circulation, including arterial remodeling and increased vascular resistance, thereby resulting in right ventricular dysfunction and cor pulmonale in these patients. ${ }^{(1)}$

The present study found negative correlations between nocturnal hypoxemia and pulmonary function values, revealed by a reduction in FVC ( $\%$ of predicted) and in $\mathrm{FEV}_{1}$ ( $\%$ of predicted). The effects of the severity of lung disease on sleep have been reported in previous studies ${ }^{(20,21)}$; however, only patients with moderate or severe 

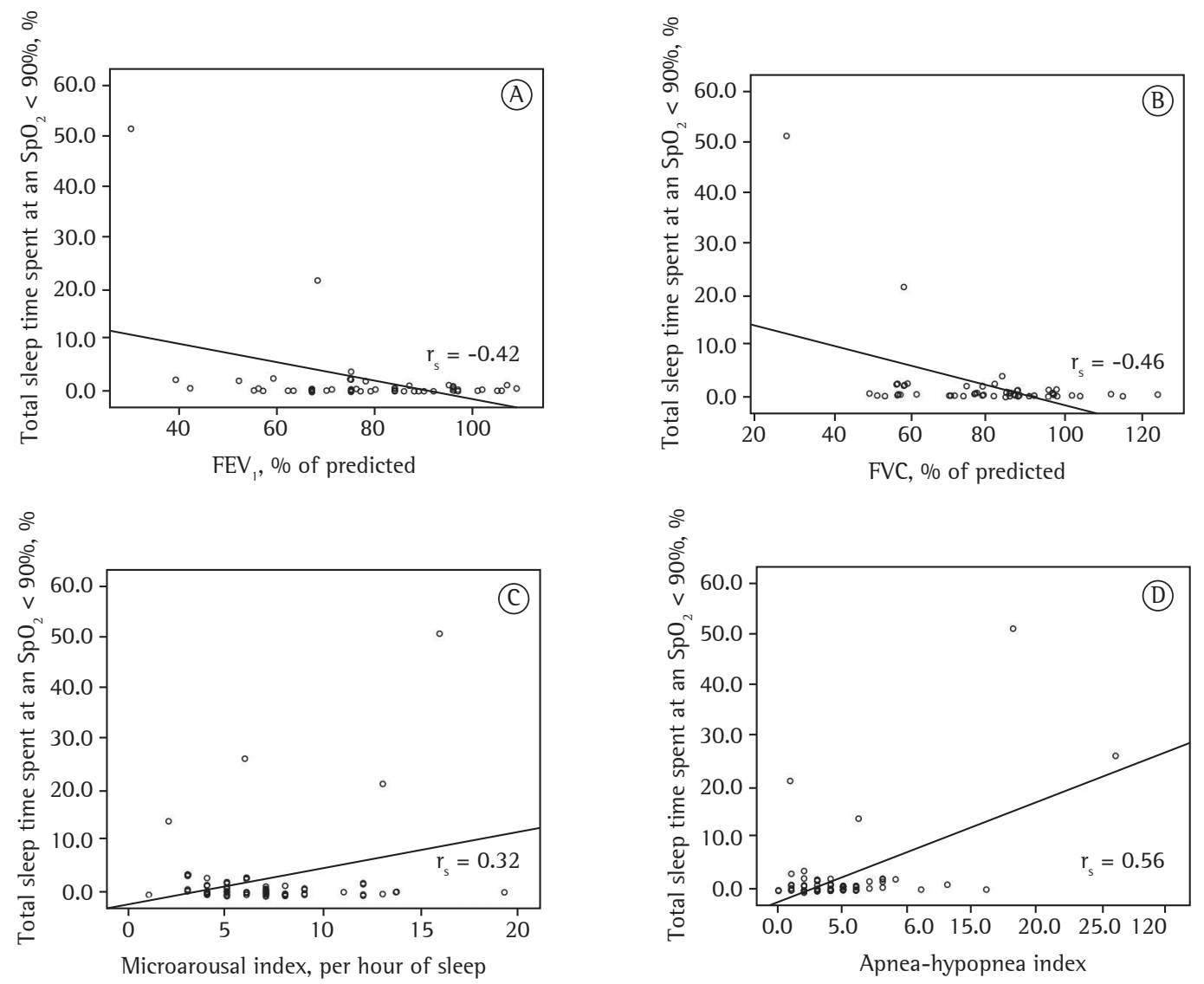

Figure 1 - Representation of the correlations between the proportion of total sleep time spent at an $\mathrm{SpO}_{2}$ $<90 \%$ and the following: $\mathrm{FEV}_{1}$ ( $\%$ of predicted; in A); FVC (\% of predicted; in B); microarousal index (per hour of sleep; in C); and apnea-hypopnea index (in D).

disease were studied. The FEV variable has been proposed as a simple parameter to identify patients at risk for nocturnal desaturation. ${ }^{(22)}$

In the present study, the patients who had hypoxemia during sleep spent a greater proportion of time in stage R sleep. Hypoventilation has been reported in patients with CF during this stage of sleep, ${ }^{(23)}$ and this might explain our finding; it is possible that the occurrence of a large number of apnea and hypopnea events during this stage of sleep, which are associated with hypoventilation, contributed to increased sleep fragmentation. In addition, we found a positive correlation between nocturnal hypoxemia and the number of microarousals; therefore, nocturnal desaturation would be related to lower sleep efficiency, a finding that is supported by data published in other studies. ${ }^{(1,5)}$ Amin et al. ${ }^{(20)}$ reported that, in their study sample, children with CF had lower sleep efficiency and more frequent awakenings than did those without CF. However, the literature offers conflicting results regarding abnormalities in sleep macrostructure in patients with CF. ${ }^{(24,25)}$

Another important finding of the present study was that $13.4 \%$ of the patients studied had obstructive sleep apnea syndrome (OSAS), a prevalence that is higher than the data reported in the literature. ${ }^{(17,18)}$ In addition to being a major cause of nocturnal sleep fragmentation, OSAS might be associated with hypoxemia during sleep in patients with CF. ${ }^{(25)}$ Spicuzza et al., ${ }^{(26)}$ who studied a population of children with CF and a mean age similar to that of our study population, found that $28(70 \%)$ of 40 children had mildto-moderate OSAS (defined as an $\mathrm{AHI}>2$ ). In a previous study of a similar patient population, Ramos et al. ${ }^{(27)}$ showed that the patients with OSAS had signs of chronic rhinosinusitis. In the present study, we found that nasal polyposis, which is a 
characteristic of chronic rhinosinusitis, was more common in patients with hypoxemia during sleep than in those without ( $p=0.05$ ), as was OSAS; however, regarding OSAS, there was no statistical significance between the groups $(p=0.21)$. We found a positive correlation between nocturnal hypoxemia and $\mathrm{AHI}\left(\mathrm{r}_{\mathrm{s}}=0.56\right)$. It is possible that OSAS in these patients contributed to the frequent sleep disruptions; data in the literature show that sleep fragmentation can adversely affect many aspects of children's lives and of their behavioral and neurocognitive development. ${ }^{(28,29)}$ However, Naqvi et al., ${ }^{(30)}$ who evaluated children and adolescents with CF, observed that the severity of lung disease was associated with the severity of sleep disruption.

The strength of our study included the evaluation of clinical stable patients in order to limit variability in nocturnal oxyhemoglobin desaturation, which occurs during CF exacerbations, and the use of laboratory polysomnography, which allowed the observation of abnormalities in sleep architecture. However, there are limitations that need to be considered. The study was crosssectional in design, which precludes causal inferences. In addition, we identified the need for a larger sample in order to correct all potential confounding factors, as well as for a balance between the number of patients with and the number of patients without hypoxemia during sleep in order to provide power to the study.

In conclusion, our study showed that nocturnal hypoxemia is common in clinically stable children and adolescents with CF, being associated with abnormalities in pulmonary function and sleep macrostructure, as well as with OSAS. Future studies are needed to evaluate the effects of nocturnal hypoxemia on clinical outcomes; our findings draw attention to the need to include nocturnal polysomnography and cardiorespiratory monitoring in the routine evaluation of patients with $\mathrm{CF}$, as well as to prescribe nocturnal home oxygen therapy.

\section{References}

1. Urquhart DS, Montgomery H, Jaffé A. Assessment of hypoxia in children with cystic fibrosis. Arch Dis Child. 2005;90(11):1138-43. http://dx.doi.org/10.1136/ adc.2005.071795 PMid:16243867 PMCid:PMC1720198

2. Fauroux B. Why, when and how to propose noninvasive ventilation in cystic fibrosis? Minerva Anestesiol. 2011;77(11):1108-14. PMid:21602746

3. Ballard RD, Sutarik JM, Clover CW, Suh BY. Effects of non-REM sleep on ventilation and respiratory mechanics in adults with cystic fibrosis. Am J Respir Crit Care Med. 1996;153(1):266-71. http://dx.doi.org/10.1164/ ajrccm.153.1.8542127 PMid:8542127

4. Villa MP, Pagani J, Lucidi V, Palamides S, Ronchetti R. Nocturnal oximetry in infants with cystic fibrosis. Arch Dis Child. 2001;84(1):50-4. http://dx.doi.org/10.1136/ adc.84.1.50 PMid:11124784 PMCid:PMC1718605

5. Young AC, Wilson JW, Kotsimbos TC, Naughton MT. The impact of nocturnal oxygen desaturation on quality of life in cystic fibrosis. J Cyst Fibros. 2011;10(2):100-6. http:// dx.doi.org/10.1016/j.jcf.2010.11.001 PMid:21195036

6. Fraser KL, Tullis DE, Sasson Z, Hyland RH, Thornley KS, Hanly PJ. Pulmonary hypertension and cardiac function in adult cystic fibrosis: role of hypoxemia. Chest. 1999;115(5):1321-8. http://dx.doi.org/10.1378/ chest.115.5.1321 PMid:10334147

7. Borriello G, Werner E, Roe F, Kim AM, Ehrlich GD, Stewart PS. Oxygen limitation contributes to antibiotic tolerance of Pseudomonas aeruginosa in biofilms. Antimicrob Agents Chemother. 2004;48(7):2659-64. http://dx.doi. org/10.1128/AAC.48.7.2659-2664.2004 PMid:15215123 PMCid:PMC434183

8. Frangolias DD, Wilcox PG. Predictability of oxygen desaturation during sleep in patients with cystic fibrosis: clinical, spirometric, and exercise parameters. Chest. 2001;119(2):434-41. http://dx.doi.org/10.1378/ chest.119.2.434

9. Lessa 1, Magalhães L, Araújo MJ, de Almeida Filho N, Aquino E, Oliveira MM. Arterial hypertension in the adult population of Salvador (BA)--Brazil. Arq Bras Cardiol. 2006;87(6):747-56. http://dx.doi.org/10.1590/S0066782X2006001900011 PMid:17262113

10. Shwachman H, Kulczycki Ll. Long-term study of one hundred five patients with cystic fibrosis; studies made over a five- to fourteen-year period. AMA J Dis Child. 1958;96(1):6-15. http://dx.doi.org/10.1001/ archpedi.1958.02060060008002

11. Frisancho AR. Anthropometric standards for the assessment of growth and nutritional status. Ann Arbor: University of Michigan Press; 1990. p. 31-42.

12. Iber C, Ancoli-lsrael S, Chesson A Jr, Quan S, editors. The AASM Manual for the scoring of sleep and associated events: rules, terminology and technical specifications. Westchester, IL: American Academy of Sleep Medicine; 2007 PMCid:PMC2134956

13. Standardization of Spirometry, 1994 Update. American Thoracic Society. Am J Respir Crit Care Med. 1995;152(3):1107-36. http://dx.doi.org/10.1164/ ajrccm.152.3.7663792 PMid:7663792

14. Sociedade Brasileira de Pneumologia e Tisiologia. Diretrizes para Teste de Função Pulmonar. J Pneumol. 2002;28(Suppl 3):S1-S238.

15. Knudson RJ, Lebowitz MD, Holberg CJ, Burrows B. Changes in the normal maximal expiratory flow-volume curve with growth and aging. Am Rev Respir Dis. 1983;127(6):72534. PMid:6859656

16. IBM Corp. Released 2010. IBM SPSS Statistics for Windows, Version 13.0. Armonk, NY: IBM Corp.

17. Uyan ZS, Ozdemir N, Ersu R, Akpinar I, Keskin S, Cakir E, et al. Factors that correlate with sleep oxygenation in children with cystic fibrosis. Pediatr Pulmonol. 2007;42(8):716-22. http://dx.doi.org/10.1002/ppul.20643 PMid:17595040

18. de Castro-Silva C, de Bruin VM, Cavalcante AG, Bittencourt LR, de Bruin PF. Nocturnal hypoxia and sleep disturbances 
in cystic fibrosis. Pediatr Pulmonol. 2009;44(11):1143-50. http://dx.doi.org/10.1002/ppul.21122 PMid:19824056

19. Perin C, Fagondes SC, Casarotto FC, Pinotti AF, Menna Barreto SS, Dalcin Pde T. Sleep findings and predictors of sleep desaturation in adult cystic fibrosis patients. Sleep Breath. 2012;16(4):1041-8. http://dx.doi.org/10.1007/ s11325-011-0599-5 PMid:21948072

20. Amin R, Bean J, Burklow K, Jeffries J. The relationship between sleep disturbance and pulmonary function in stable pediatric cystic fibrosis patients. Chest. 2005;128(3):1357-63. http://dx.doi.org/10.1378/ chest.128.3.1357 PMid:16162729

21. Jankelowitz L, Reid KJ, Wolfe L, Cullina J, Zee PC, Jain M. Cystic fibrosis patients have poor sleep quality despite normal sleep latency and efficiency. Chest. 2005;127(5):1593-9. http://dx.doi.org/10.1378/ chest.127.5.1593 PMid:15888833

22. Fauroux B, Pepin JL, Boelle PY, Cracowski C, Murris-Espin $\mathrm{M}$, Nove-Josserand R, et al. Sleep quality and nocturnal hypoxaemia and hypercapnia in children and young adults with cystic fibrosis. Arch Dis Child. 2012;97(11):960-6. http://dx.doi.org/10.1136/archdischild-2011-300440 PMid:22984185

23. Milross MA, Piper AJ, Norman M, Willson GN, Grunstein RR, Sullivan CE, et al. Night-to-night variability in sleep in cystic fibrosis. Sleep Med. 2002;3(3):213-9. http:// dx.doi.org/10.1016/S1389-9457(02)00030-8

24. Dancey DR, Tullis ED, Heslegrave R, Thornley K, Hanly PJ. Sleep quality and daytime function in adults with cystic fibrosis and severe lung disease. Eur Respir J. 2002;19(3):504-10. http://dx.doi.org/10.1183/09031 936.02.00088702 PMid:11936530
25. Milross MA, Piper AJ, Dobbin CJ, Bye PT, Grunstein RR. Sleep disordered breathing in cystic fibrosis. Sleep Med Rev. 2004;8(4):295-308. http://dx.doi.org/10.1016/j. smrv.2004.03.004 PMid:15233957

26. Spicuzza L, Sciuto C, Leonardi S, La Rosa M. Early occurrence of obstructive sleep apnea in infants and children with cystic fibrosis. Arch Pediatr Adolesc Med. 2012;166(12):1165-9. http://dx.doi.org/10.1001/ archpediatrics.2012.1177 PMid:23090511

27. Ramos RT, Salles C, Gregório PB, Barros AT, Santana A, Araújo-Filho JB, et al. Evaluation of the upper airway in children and adolescents with cystic fibrosis and obstructive sleep apnea syndrome. Int J Pediatr Otorhinolaryngol. 2009;73(12):1780-5. http://dx.doi. org/10.1016/j.ijporl.2009.09.037 PMid:19854521

28. Halbower AC, Degaonkar M, Barker PB, Earley CJ, Marcus $\mathrm{CL}$, Smith PL, et al. Childhood obstructive sleep apnea associates with neuropsychological deficits and neuronal brain injury. PLoS Med. 2006;3(8):e301. http://dx.doi. org/10.1371/journal.pmed.0030301 PMid:16933960 PMCid:PMC1551912

29. Giordani B, Hodges EK, Guire KE, Ruzicka DL, Dillon JE, Weatherly RA, et al. Changes in neuropsychological and behavioral functioning in children with and without obstructive sleep apnea following Tonsillectomy. J Int Neuropsychol Soc. 2012;18(2):212-22. http://dx.doi. org/10.1017/S1355617711001743 PMid:22272653

30. Naqvi SK, Sotelo C, Murry L, Simakajornboon N. Sleep architecture in children and adolescents with cystic fibrosis and the association with severity of lung disease. Sleep Breath. 2008;12(1):77-83. http://dx.doi.org/10.1007/ s11325-007-0123-0 PMid:17610099

\section{About the authors}

\section{Regina Terse Trindade Ramos}

Adjunct Professor 11. Department of Pediatrics, Federal University of Bahia School of Medicine, Salvador, Brazil.

\section{Maria Angélica Pinheiro Santana}

Coordinator. Bahia State Referral Center for Cystic Fibrosis, Salvador, Brazil.

\section{Priscila de Carvalho Almeida}

Medical Student. Department of Pediatrics, Federal University of Bahia School of Medicine, Salvador, Brazil.

\section{Almério de Souza Machado Júnior}

Adjunct Professor. Bahia School of Medicine and Public Health, Bahia Foundation for Science Development, Salvador, Brazil.

\section{José Bouzas Araújo-Filho}

Statistician. Collective Health Institute, Federal University of Bahia, Salvador, Brazil.

\section{Cristina Salles}

Sleep Specialist. Graduate Course in Medicine and Health Sciences, Federal University of Bahia School of Medicine, Salvador, Brazil. 